\title{
Prophylactic Gabapentin for Prevention of Postoperative Nausea and Vomiting in Patients Undergoing Laparoscopic Surgery
}

\author{
${ }^{1}$ Dr Sourabh Roy ${ }^{1,}$ Dr Krishna Gupta ${ }^{2}$ \\ ${ }^{1}$ Associate Professor ${ }^{2}$ Professor and HOD Department of Anaesthesiology, KPC Medical College
}

\begin{abstract}
Context: Prevention and treatment of postoperative nausea and vomiting continues to be a major challenge in postoperative care. Gabapentin is an antiepileptic drug. Its antiepileptic action is demonstrated in chemotherapy-induced acute and delayed onset of nausea and vomiting in breast cancer patient.

Aims: The aim of this study was to evaluate the antiemetic effect of gabapentin on incidence and severity of postoperative nausea and vomiting in laparoscopic surgery.

Methods and Material: Sixty adult patients of ASA grade I \& II scheduled for laparoscopic surgeries like lap appendicectomy, lap cholecystectomy, lap hernia repair were randomly assigned into two equal groups to receive $600 \mathrm{mg}$ gabapentin (Group $G, n=30$ ) or matching placebo (Group $P, n=30$ ) two hours prior to surgery. Conventional anaesthesia technique was applied to every patient. Ondansetron $4 m g$ was used intravenously as rescue medication for emesis.

Statistical analysis used: Incidence and severity of postoperative nausea and vomiting (PONV) were compared between the study groups in the next 12 hours.

Results: Demographic data and the duration of anaesthesia were not significantly different between the two study groups. Six patients in group $G$ had PONV in 12 hours compared with 18 patients in group $P(P<0.05)$. Eighteen patients (60\%) in group $G$ had no incidence of PONV in comparison with twelve patients (40\%) in group $P(P<0.05)$.

Conclusions: Administration of oral gabapentin before laparoscopic surgery effectively suppresses nausea and vomiting.
\end{abstract}

Keywords: Antiemetic, gabapentin, postoperative nausea, vomiting.

\section{Introduction}

Postoperative nausea and vomiting are commonly occurring complications following anaesthesia and surgery ${ }^{1,2}$. Prevention and treatment of PONV continues to be a major challenge in postoperative care and plays an important role in well-being of the surgical patients. Several factors are responsible for the etiology of PONV including the technique of anaesthesia, type and site of surgery, gender. Now-a-days laparoscopic procedure has become more popular compared to conventional open technique. Incidence of PONV is more in laparoscopic operation than open technique. It is seen that nearly $53-72 \%$ of patients require antiemetic therapy after laparoscopic surgery, whereas the incidence of PONV in patients undergoing general anaesthesia for conventional surgery is $30 \%^{3,4}$.

The probable cause of PONV in laparoscopic surgery is peritoneal stretching due to intraperitoneal $\mathrm{CO}_{2}$ insufflation Gabapentin is an anticonvulsant that has antinociceptive and antihyperalgesic properties. It is a structural analog of gamma amino butyric acid (GABA). It does not bind with plasma proteins and is not metabolized in humans. After a single oral dose of $300 \mathrm{mg}$, mean maximum plasma concentrations attained in 23 hours. Absorption kinetics of gabapentin is dose-dependent, due to a saturable transport system. The bioavailability of a single $300 \mathrm{mg}$ oral dose of gabapentin is $60 \%$ and decreases with increasing dose. Elimination of gabapentin is by renal clearance and elimination half-life is about 5-7 hour after a single oral dose of 200-400mg. ${ }^{5,6,7}$.

Recently it is reported the anti-emetic effect of gabapentin in chemotherapy-induced acute (within 24 hour) and delayed onset (2-5 days) of nausea and vomiting in breast cancer ${ }^{8}$. In this study, we have evaluated the antiemetic effect of gabapentin on the incidence and severity of PONV in patients who underwent laparoscopic surgery.

There are several drugs used to prevent PONV like metoclopramide, ondansetron etc.They deserve some severe adverse effects like extra-pyramidal symptoms etc. On the other hand, they do not decrease postoperative rescue analgesic requirement.

In the study by Pandey et al. ${ }^{3}$ on 250 patients scheduled for laparoscopic cholecystectomy, gabapentin as premedication effectively suppresses nausea and vomiting and post-operative rescue analgesic requirement. Therefore, we designed a placebo-controlled study to test the hypothesis that oral gabapentin $600 \mathrm{mg}$ as premedication, would decrease the incidence and severity of PONV in laparoscopic surgery. 


\section{Subjects And Methods}

This clinical trial was performed from January 2016 to April 2016.After taking approval from the Institutional Ethical Committee, written informed consent was taken from each patient separately. We recruited 60 patients of ASA physical status $1 \& 2$, of both sexes scheduled for elective laparoscopic surgery for a doubleblind, prospective, randomized and placebo-controlled study.

The patients whose body weight more than $20 \%$ of ideal body weight, who had impaired liver or kidney function, received antiemetic within 24 hours, who were menstruating ,pregnant or lactating women, history of motion sickness or on an antidepressant or converted to open techniques were excluded from the study. The patients were randomly allocated into two equal groups. The patients of group $\mathrm{G}$ received oral gabapentin $600 \mathrm{mg}(n=30)$ and the patients of group $P$ received matching placebo $(n=30) 2$ hour before surgery. Randomization was based on computer generated codes that were concealed until interactions were assigned. Tablet alprazolam (0.5) was given to every patient in the night before surgery and on arrival in the operating room, standard anaesthesia monitors were applied. Anaesthesia was induced with propofol $2 \mathrm{mg} / \mathrm{kg}$, tramadol $1 \mathrm{mg} / \mathrm{kg}$. Tracheal intubation was facilitated with rocuronium bromide $0.9 \mathrm{mg} / \mathrm{kg}$. Anaesthesia was maintained with propofol infusion at the rate of $100 \mathrm{microgram} / \mathrm{kg} / \mathrm{min}$ and $70 \%$ nitrous oxide in oxygen and intermittent vecuronium bromide when indicated. At the end of operation, neuromuscular blockade was reversed with glycopyrolate $(0.01 \mathrm{mg} / \mathrm{kg})$ and neostigmine $(0.04 \mathrm{mg} / \mathrm{kg})$ and extubation was done. Patients were shifted to postanaesthesia care unit (PACU) for 6 hour and then shifted to their respective wards. A resident doctor, who was blind to the type of medication the patients had received, recorded PONV at 1, 3, $6 \& 12$ hours. Intravenous tramadol was used if the pain score was $>3$ (VAS score) or on patient demand within 12 hours. Any adverse effect was also noted. Intra \&postoperative $\mathrm{BP}$, pulse, $\mathrm{spO}_{2}$ were noted for all the patients of both the groups.

\section{Statistical Analysis}

The arithmetic means and the standard error of means (mean \pm SEM) of percentage (\%) of type of nausea \&vomiting in each of the treated (Group G) and Placebo (Group P) groups were calculated. The data were analyzed by one way analysis of variance (ANOVA), where $\mathrm{F}$ values indicated significance and means were compared by a post-hoc multiple range test with $P<0.05$ taken as the statistically significant threshold.

\section{Results}

All patients in both groups were comparable according to age, body weight, ASA status, duration of surgey and duration of anaesthesia (Table I). There was no statistically significant difference regarding the type of operation between the two study groups (Table 2).Intraoperative and postoperative vital parameters were more or less same in both groups. The difference was not statistically significant(Table 3). The incidence of PONV during first 12 hour in patients after laparoscopic surgery was significantly lower in gabapentin group then placebo group regarding no vomiting, mild vomiting and moderate vomiting and the result is statistically significant $(P<0.05)$. But there was no statistically significant difference in the severity of PONV amongst the two groups (Table $4 \&$ Table $5 \&$ Figure 1 ).

The total number of patients $(4 / 30)$ requiring $1^{\text {st }}$ dose of rescue antiemetic was much less than placebo group (30/30). The difference in both groups was statistically significant $(P<0.05)$ (Table 6 \& Figure 2).Regarding $2^{\text {nd }}$ dose rescue antiemetic, it was nil in GrG whereas 18 patients $(60 \%)$ of Group $P$ received $2^{\text {nd }}$ dose of antiemetic $(P<0.05)$ (Table 6).The patients of placebo group consumed significantly higher amount ondansetron as antiemetic $(P<0.05)$ and tramadol as analgesic compared to the patients of Gabapentin group (Table 7 \& 8).

The incidence of side effects in both the groups was similar and few. Drowsiness and headache was observed in a very few patients of Group G. The result was not statistically significant (Table 9).

\section{Discussion}

Gabapentin is mainly used as an analgesic. Gabapentin has been demonstrated to decrease opioids consumption in postoperative as well as painful neuropathic conditions ${ }^{9,10,11,12}$.

Antihyperalgesic properties of gabapentin are by reducing central sensitization, a pre-requisite for postoperative hyperalgesia. It binds with the alpha $2 \delta$ subunit of voltage dependent calcium channels and blocks the development of hyperalgesia and controls sensitization ${ }^{13,14 .}$.

PONV was defined as the subjective unpleasant sensation associated with awareness of urge to vomit (nausea, retching, vomiting had been grouped together). The severity of PONV was graded as follows:No Ponv

Absence of any emetic episode or nausea

Mild Ponv

The patient had only mild nausea or one emetic episode or short lasting nausea of any severity of less than 10 minutes which triggered by exogenous stimulus no antiemetic drug was required. 
Moderate ponv

The patient had 1-2 emetic episodes or moderate or severe nausea without exogenous stimulus and patient required antiemetic therapy once.

Severe ponv

The patient had more than two emetic episodes or was nauseated more than twice and administration of at least one antiemetic was required. Recently gabapentin has been reported to be effective in the treatment of nausea \&vomiting in patient receiving cytotoxic drugs ${ }^{8}$. Although the etiology of PONV in patient undergoing laparoscopic surgery is not same as that in patients receiving cytotoxic drugs, in our study we found that there was lower incidence of PONV during first 12 hour after laparoscopic surgery in the group of patient who received prophylactic Gabapentin $600 \mathrm{mg}$ two hours before surgery than those who received placebo. In a study by Pandey et $\mathrm{al}^{3}$ it was found that incidence of postoperative nausea and vomiting within 24 hour after laparoscopic cholecystectomy was significantly lower in gabapentin group than in the placebo group $(\mathrm{P}=0.04)$.

But Sussan Soltani and Mirsadegh ${ }^{15}$ showed in their study that oral gabapentin $300 \mathrm{mg}$ 1hour before surgery was effective in reducing postoperative nausea but not vomiting.

In our study we found that more than $80 \%$ of patients of group $G$ have no vomiting and a few percentage of patients have been suffering from mild \& moderate type of vomiting $(\mathrm{P}<0.05)$. This is correlated with the study of Pandey et al ${ }^{3}$.

Probably the cause of ineffective vomiting control in the study of Sussan Soltani and Mirsadegh ${ }^{15}$ is due to low dose of gabapentin and early ambulation.

The mechanism of gabapentin in the prevention of PONV is unknown but it could possibly be due to the indirect effect of opioid sparing or a direct effect on tachykinin activity ${ }^{16}$.

Study by Bashir et al ${ }^{17}$ showed that the additional use of rescue antiemetics was reduced in that group treated with gabapentin (34\%) compared to placebo group $(54 \%)(\mathrm{P}<0.05)$. Our study also showed that only 4 patients $(13.33 \%)$ of $\mathrm{Gr} \mathrm{G}$ received first dose antiemetic drug compared to Gr P where all patients received first dose of antiemetic. This difference is statistically significant $(\mathrm{P}<0.05 \%)$. Second dose of antiemetic was not required in Gr G. But $60 \%$ of patients in Gr P received second dose of antiemetic. This difference is statistically significant $(\mathrm{P}<0.05)$.It is also shown that the total dose of antiemetic was also markedly reduced in $\mathrm{Gr} G$ as compared to GrP.This is also confirmed in the studies by different authors ${ }^{3,18}$.

In our study in the patients of Gr G received lower amount of analgesic postoperatively than those the patients of $\mathrm{Gr} \mathrm{P}(\mathrm{P}<0.05)$. This observation was same as the observation of different authors ${ }^{9,10,11}$.

Gabapentin was well tolerated with no significant side effects in this study. A few patients (6/30), however, suffered from headache of moderate intensity postoperatively.

\section{Conclusion}

To conclude, a single dose of gabapentin $600 \mathrm{mg}$ as premedication decreases PONV significantly. It also reduces postoperative oral analgesic consumption. Further studies however are required to investigate the efficacy of this drug alone or in combination with other antiemetic.

\section{References}

[1]. Naguib M, el Bakry AK, Khoshim MH, et al. Prophylactic antiemetic therapy with ondansetron, tropisetron, granisetron and metoclopramide in patients undergoing laparoscopic cholecystectomy: a randomized, double blind comparison with placebo. Can $\mathrm{J}$ Anaesth $1996 ; 43: 226-31$.

[2]. Cohen MM, Duncan PG, DeBoer DP, Tweed WA. The postoperative interview: assessing risk factors for nausea and vomiting. Anesth Analg 1994; 78:7-16.

[3]. Pandey CK, Priye S, Ambesh SP, Singh S, Singh U, Singh PK. Prophylactic gabapentin for prevention of postoperative nausea and vomiting in patients undergoing laparoscopic cholecystectomy: a randomized, double-blind, placebo-controlled study. J Postgrad Med 2006; 52:97-100.

[4]. Camu F, Lauwers MH, Verbessem D. Incidence \& aetiology of PONV. Eur .J. Anaesthesiol 1992; 9: 25-31

[5]. Goa KL, Sorkin EM. Gabapentin. A review of its pharmacological properties and clinical potential in epilepsy. Drugs 1993;46:40927

[6]. Mathiesen O, Imbimbo BP, Hilsted KL, Fabbri L, Dahl JB. CHF3381, a N-methyl-D-aspartate receptor antagonist and monoamine oxidase-A inhibitor, attenuates secondary hyperalgesia in a human pain model. J Pain 2006; 7:565-74

[7]. Eckhardt K, Ammon S, Hofmann U, Riebe A, Gugeler N, Mikus G. Gabapentin enhances the analgesic effect of morphine in healthy volunteers. Anesth Analg. 2000;91:185-91.

[8]. Guttuso T Jr, Roscoe J, Griggs J. Effect of gabapentin on nausea induced by chemotherapy in patients with breast cancer. Lancet 2003; 361:1703-5

[9]. Dierking G, Duedahl TH, Rasmussen ML, et al. Effects of gabapentinon postoperative morphine consumption and pain after abdominal hysterectomy: a randomized, double-blind trial. Acta Anaesthesiol Scand 2004; 48:322-7.

[10]. Dirks J, Fredensborg BB, Christensen D, Fomsgaard JS, Flyger H, Dahl JB. A randomized study of the effects of single-dose gabapentin versus placebo on postoperative pain and morphine consumption after mastectomy. Anesthesiology 2002; 97:560-4.

[11]. Fassoulaki A, Patris K, Sarantopoulos C, Hogan Q. The analgesic effect of gabapentin and mexiletine after breast surgery for cancer. Anesth Analg 2002; 95:985-91.

[12]. Nikolajsen L, Finnerup NB, Kramp S, Vimtrup AS, Keller J, Jensen TS. A randomized study of the effects of gabapentin on postamputation pain. Anesthesiology 2006; 105:1008-15. 
[13]. Fink K, Dooley DJ, Meder WP, et al. Inhibition of neuronal $\mathrm{Ca}^{2+}$ influx by gabapentin and pregabalin in the human neocortex. Neuropharmacology 2002; 42:229-36.

[14]. Gee NS, Brown JP, Dissanayake VU, Offord J, Thurlow R, Woodruff GN. The novel anticonvulsant drug, gabapentin (Neurontin), binds to the $\alpha_{2} \delta$ subunit of a calcium channel. J Biol Chem 1996; 271:5768-76.

[15]. Sussan Soltani Mohammadi, Mirsadegh Seyedi. Comparing oral gabapentin versus clonidine as premedication on early postoperative pain, nausea and vomiting following general anesthesia. Saudi Journal of Anaesthesia 2009; $3: 25-28$.

[16]. Maneuf YP, Hughes J, McKnight AT. Gabapentin inhibits the substance P- facilitated $\mathrm{K}^{+}$evoked release of [3H]glutamate from rat caudal trigeminal nucleus slices. Pain 2001; 93:191-6.

[17]. Farhana Bashir, Kharat Mohd, Shigufta Qazi, A.M. Hashia. A Randomized, double blind, placebo controlled study evaluating preventive role of Gabapentin for PONV in patients undergoing laparascopic cholecystectomy. JK Science 2009;11(4): 190-193

[18]. Rorarius MGF, Mennander S, Suominen P, et al. Gabapentin for the prevention of postoperative pain after vaginal hysterectomy. Pain 2004; 110:175-81.

Table 1: Demographic and Perioperative data

Values are expressed Values are expressed as mean \pm SD

\begin{tabular}{|l|l|l|}
\hline Characteristics & Group G & Group P \\
\hline Age(years) & $30 \pm 6.4$ & $30 \pm 6.1$ \\
\hline Weight(Kg) & $67.7+\_9.4$ & $68.1+\_10.3$ \\
\hline ASA(I/II) & $24 / 6$ & $25 / 5$ \\
\hline Duration of surgery (mins) & $51.8 \pm 9.6$ & $52.1 \pm 9.3$ \\
\hline Anaesthesia time (mins) & $56.5 \pm 3$ & $57.4 \pm 5$ \\
\hline
\end{tabular}

Table 2: Types of operation

\begin{tabular}{|l|l|l|}
\hline No. of patients & Group $\mathrm{G}(\mathrm{n}=30)$ & Group $\mathrm{P}(\mathrm{n}=30)$ \\
\hline Lap. Appendicectomy & 8 & 9 \\
\hline Lap. Cholecystectomy & 14 & 13 \\
\hline Lap. Hernia repair & 3 & 4 \\
\hline Lap. Ovarian cystectomy & 5 & 4 \\
\hline Total & 30 & 30 \\
\hline
\end{tabular}

Table 3: Intra and postoperative vital parameters

\begin{tabular}{|l|l|l|l|l|}
\hline Characteristics & \multicolumn{3}{|l|}{ Group G } & Group P \\
\hline Period & Intra op & post op & Intra op & post op \\
\hline Heart rate & $80.3 \pm 6.2$ & $74 \pm 4.6$ & $78.5 \pm 5.4$ & $76.4 \pm 3.4$ \\
\hline $\begin{array}{l}\text { Mean Blood Pressure } \\
\text { (mm Hg) }\end{array}$ & $102.5 \pm 8.1$ & $96.8 \pm 10.6$ & $101.4 \pm 7.8$ & $98.4 \pm 9.8$ \\
\hline Respiratory rate & $18.3 \pm 3.6$ & $16.6 \pm 3.4$ & $17.6 \pm 2.8$ & $17.2 \pm 2.5$ \\
\hline $\mathrm{SpO}_{2}$ & $99.3 \pm 0.5$ & $99.1 \pm 0.8$ & $99.2 \pm 0.4$ & $99.4 \pm 0.2$ \\
\hline
\end{tabular}

Values are expressed as mean \pm SD

Table 4: Postoperative Nausea and Vomiting (PONV)

\begin{tabular}{|l|l|l|l|l|l|l|l|l|}
\hline Group & \multicolumn{9}{|l}{$\begin{array}{l}\text { Group G } \\
\text { (N=30) }\end{array}$} & \multicolumn{2}{l|}{$\begin{array}{l}\text { Group P } \\
(\mathrm{N}=30)\end{array}$} \\
\hline $\begin{array}{l}\text { Time } \\
(\mathrm{hrs})\end{array}$ & $\begin{array}{l}\text { No } \\
\text { Vomiting }\end{array}$ & $\begin{array}{l}\text { Mild } \\
\text { Vomiting }\end{array}$ & $\begin{array}{l}\text { Moderate } \\
\text { Vomiting }\end{array}$ & $\begin{array}{l}\text { Severe } \\
\text { Vomiting }\end{array}$ & $\begin{array}{l}\text { No } \\
\text { Vomiting }\end{array}$ & $\begin{array}{l}\text { Mild } \\
\text { Vomiting }\end{array}$ & $\begin{array}{l}\text { Moderate } \\
\text { Vomiting }\end{array}$ & $\begin{array}{l}\text { Severe } \\
\text { Vomiting }\end{array}$ \\
\hline 1 & $24 / 30$ & $5 / 30$ & $1 / 30$ & $0 / 30$ & $0 / 30$ & $9 / 30$ & $18 / 30$ & $3 / 30$ \\
& $(80 \%)$ & $(16.66 \%)$ & $(3.33 \%)$ & $(0 \%)$ & $(0 \%)$ & $(30 \%)$ & $(60 \%)$ & $(10 \%)$ \\
\hline 3 & $24 / 30$ & $2 / 30$ & $4 / 30$ & $0 / 30$ & $1 / 30$ & $10 / 30$ & $18 / 30$ & $1 / 30$ \\
& $(80 \%)$ & $(6.66 \%)$ & $(13.33 \%)$ & $(0 \% 0$ & $(3.33 \%)$ & $(33.33 \%)$ & $(60 \%)$ & $(3.33 \%)$ \\
\hline 6 & $29 / 30$ & $1 / 30$ & $0 / 30$ & $0 / 30$ & $5 / 30$ & $15 / 30$ & $10 / 30$ & $0 / 30$ \\
& $(96.66 \%)$ & $(3.33 \%)$ & $(0 \%)$ & $(0 \%)$ & $(16.66 \%)$ & $(50 \%)$ & $(33.33 \%)$ & $(0 \%)$ \\
\hline 12 & $28 / 30$ & $2 / 30$ & $0 / 30$ & $0 / 30$ & $10 / 30$ & $20 / 30$ & $0 / 30$ & $0 / 30$ \\
& $(93.66 \%)$ & $(6.66 \%)$ & $(0 \%)$ & $(0 \%)$ & $(33.33 \%)$ & $(66.66)$ & $(0 \%)$ & $(0 \%)$ \\
\hline
\end{tabular}

Table 5: Postoperative Nausea and Vomiting (PONV) - $P$ Values

\begin{tabular}{|l|l|l|l|l|}
\hline Hour & No Vomiting & Mild Vomiting & $\begin{array}{l}\text { Moderate } \\
\text { Vomiting }\end{array}$ & $\begin{array}{l}\text { Severe } \\
\text { Vomiting }\end{array}$ \\
\hline 1 & $P<0.05$ & $P<0.05$ & $P<0.05$ & NS \\
\hline 3 & $P<0.01$ & $P<0.05$ & $P<0.05$ & NS \\
\hline 6 & $P<0.05$ & $P<0.05$ & $P<0.05$ & NS \\
\hline 12 & $P<0.05$ & $P<0.05$ & NS & NS \\
\hline
\end{tabular}


Prophylactic Gabapentin For Prevention Of Postoperative Nausea And Vomiting ...

Table 6: Total number of patients requiring ondansetron as rescue antiemetic

\begin{tabular}{|l|c|c|l|}
\hline Dose & Group G(n=30) & Group P(n=30) & $P$ Value \\
\hline First dose & $4 / 30(13.33 \%)$ & $30 / 30(100 \%)$ & $P<0.05$ \\
\hline Second dose & $0 / 30(0 \%)$ & $18 / 30(60 \%)$ & $P<0.05$ \\
\hline
\end{tabular}

Table 7: Requirement of rescue analgesic

\begin{tabular}{|l|l|l|l|}
\hline Hour & Group G(n=30) & Group $\mathrm{P}(\mathrm{n}=30)$ & $P$ Value \\
\hline 1 & $3 / 30(10 \%)$ & $30 / 30(100 \%)$ & $P<0.05$ \\
\hline 3 & $5 / 30(16.66 \%)$ & $30 / 30(100 \%)$ & $P<0.05$ \\
\hline 6 & $6 / 30(20 \%)$ & $30 / 30(100 \%)$ & $P<0.05$ \\
\hline 12 & $3030(100 \%)$ & $30 / 30(100 \%)$ & $P<0.05$ \\
\hline
\end{tabular}

Table 8: Total dose of antiemetic (ondansetron) and total dose of analgesic (tramadol) required

\begin{tabular}{|l|l|l|l|}
\hline Drug of & Group G(n=30) & Group P(n=30) & $P$ Value \\
\hline $\begin{array}{l}\text { Total dose } \\
\text { ondansetron(mg) }\end{array}$ & $20 \pm 10$ & $150 \pm 10$ & $P<0.05$ \\
\hline $\begin{array}{l}\text { Total dose of } \\
\text { tramadol(mg) }\end{array}$ & $100 \pm 10$ & $150 \pm 30$ & $P<0.05$ \\
\hline
\end{tabular}

Table 9: adverse effects

\begin{tabular}{|l|l|l|l|}
\hline Adverse effects & Group G(n=30) & Group P(n=30) & P Value \\
\hline Drowsiness & $2 / 30(6.66 \%)$ & $0 / 30(0 \%)$ & NS \\
\hline Itching & $0 / 30(0 \%)$ & $0 / 30(0 \%)$ & NS \\
\hline Somnolence & $1 / 30(3.33 \%)$ & $0 / 30(0 \%)$ & NS \\
\hline Headache & $6 / 30(20 \%)$ & $0 / 30(0 \%)$ & NS \\
\hline
\end{tabular}

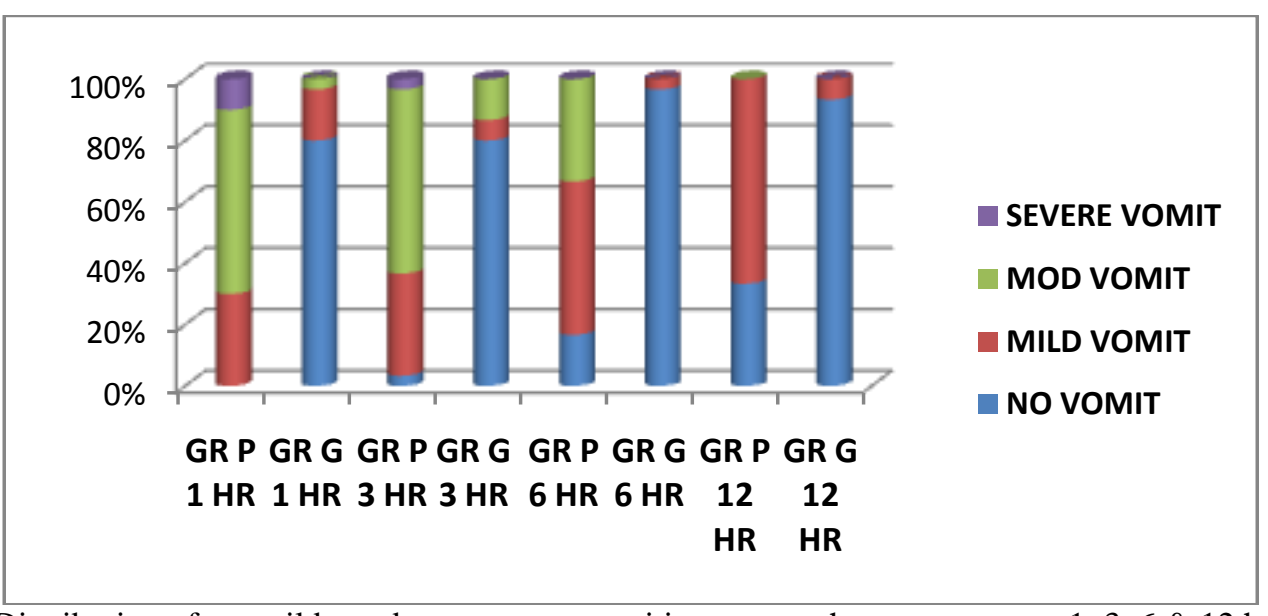

Figure 1: Distribution of no, mild, moderate, severe vomiting among the two groups at 1, 3, $6 \& 12$ hour

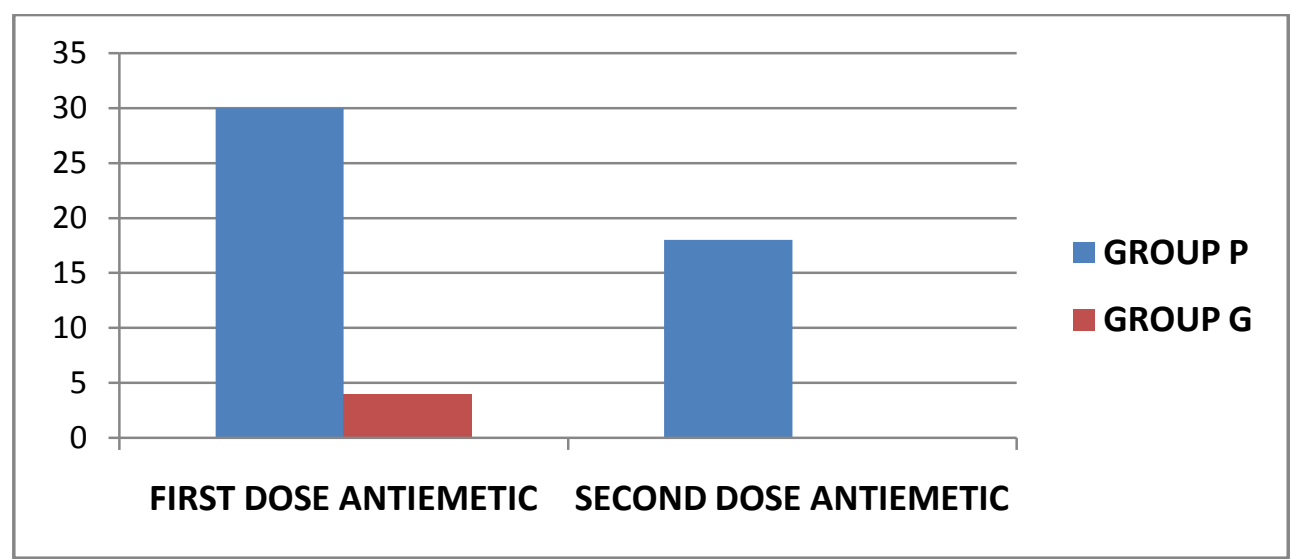

Figure 2: Total number of patients requiring ondansetron as rescue antiemetic

Corresponding author: Dr Sourabh Roy email - drsourabhroy@gmail.com 